\title{
Cannabidiol Affects MK-801-Induced Changes in the PPI Learned Response of Capuchin Monkeys (Sapajus spp.)
}

\author{
Patricia G. Saletti ${ }^{1}$, Rafael S. Maior ${ }^{1,2}$, Marilia Barros $^{3}$, Hisao Nishijo $^{4}$ and \\ Carlos Tomaz ${ }^{1,5 *}$
}

${ }^{1}$ Primate Center and Laboratory of Neurosciences and Behavior, Department of Physiological Sciences, Institute of Biology, University of Brasilia, Brasilia, Brazil, ${ }^{2}$ Department of Clinical Neuroscience, Psychiatry Section, Karolinska Institutet, Karolinska University Hospital, Stockholm, Sweden, ${ }^{3}$ Department of Pharmaceutical Sciences, School of Health Sciences, University of Brasilia, Brasilia, Brazil, ${ }^{4}$ System Emotional Science, Graduate School of Medicine and Pharmaceutical Sciences, University of Toyama, Toyama, Japan, ${ }^{5}$ Neuroscience Research Group, University CEUMA, São Luís, Brazil

\section{OPEN ACCESS}

Edited by:

Arjan Blokland

Maastricht University, Netherlands

Reviewed by: Glenn W. Stevenson,

University of New England, USA Ledia F. Hernandez,

CINAC and Hospital Universitario HM Puerta Del Sur, Spain

*Correspondence: Carlos Tomaz ctomaz@ceuma.br

Specialty section: This article was submitted to

Neuropharmacology,

a section of the journal

Frontiers in Pharmacology

Received: 05 December 2016 Accepted: 13 February 2017 Published: 27 February 2017

Citation:

Saletti PG, Maior RS, Barros M,

Nishijo H and Tomaz C (2017) Cannabidiol Affects MK-801-Induced

Changes in the PPI Learned

Response of Capuchin Monkeys

(Sapajus spp.).

Front. Pharmacol. 8:93.

doi: 10.3389/fphar.2017.00093
There are several lines of evidence indicating a possible therapeutic action of cannabidiol (CBD) in schizophrenia treatment. Studies with rodents have demonstrated that CBD reverses MK-801 effects in prepulse inhibition (PPI) disruption, which may indicate that $\mathrm{CBD}$ acts by improving sensorimotor gating deficits. In the present study, we investigated the effects of CBD on a PPI learned response of capuchin monkeys (Sapajus spp.). A total of seven monkeys were employed in this study. In Experiment 1, we evaluated the CBD (doses of 15, 30, $60 \mathrm{mg} / \mathrm{kg}$, i.p.) effects on PPI. In Experiment 2, the effects of sub-chronic MK-801 (0.02 mg/ $\mathrm{kg}$, i.m.) on PPI were challenged by a CBD pre-treatment. No changes in PPI response were observed after CBD-alone administration. However, MK-801 increased the PPI response of our animals. CBD pre-treatment blocked the PPI increase induced by MK-801. Our findings suggest that CBD's reversal of the MK-801 effects on PPI is unlikely to stem from a direct involvement on sensorimotor mechanisms, but may possibly reflect its anxiolytic properties.

Keywords: cannabidiol (CBD), MK-801, monkey, prepulse inhibition, learning, memory

\section{INTRODUCTION}

Cannabidiol (CBD) is one of the several compounds extracted from the Cannabis plant reported to have different therapeutic applications (Baker et al., 2003). These seem to include general systemic anti-inflammatory (Mechoulam et al., 2002; Vilela et al., 2015) and antioxidant properties (Hampson et al., 1998), as well as more specific effects in different neurological disorders, such as epilepsy (Mechoulam et al., 2002), anxiety (Zuardi et al., 1982; Campos and Guimarães, 2008), and schizophrenia (Zuardi et al., 1991; Leweke et al., 2012).

The antipsychotic effects, in particular, may result from the antagonistic action of CBD on cannabinoid type 1 (CB1) and 2 receptors (CB2; Thomas et al., 2007). Zuardi et al. (2012) suggested, however, that an interaction between $\mathrm{CBD}$ and anandamide is essential for the psychoactive effect, considering that $\mathrm{CBD}$ also increases the availability of this endocannabinoid via a reuptake inhibition mechanism (Mechoulam et al., 2002). The antipsychotic properties of $\mathrm{CBD}$ have also been linked to changes in glutamate signaling that results from the activation of the vanilloid TRPV type 1 receptor system. Anandamide (Di Marzo et al., 2001) and CBD (Cristino et al., 2006) are both known TRPV1 receptor ligands, and the pre-synaptic activation of this 
system increases the release of glutamate in psychosis-related areas of the brain (Xing and Li, 2007). Furthermore, CBD is reported to reverse the prepulse inhibition (PPI) disruption induced by the non-competitive glutamate NMDA receptor antagonist dizocilpine (MK-801) in murine models (Long et al., 2006; Gomes et al., 2014; Levin et al., 2014; however, see Gururajan et al., 2011), with this effect being antagonized by the TRPV1 receptor antagonist capsazepine (Long et al., 2006).

In fact, MK-801 has become a frequently used pharmacological tool to induce schizophrenic-like symptoms in pre-clinical experimental setups (Arai et al., 2008; Park et al., 2014; Saletti et al., 2015). Schizophrenic patients commonly demonstrate significant deficits in sensorimotor gating (Braff et al., 2001). This dissociative anesthetic is also reported to disrupt the PPI responding of rodents (Hoffman et al., 1993), as well as to induce cognitive (Hikichi et al., 2013; Karamihalev et al., 2014) and social recognition deficits (Yoshimi et al., 2015) and hyperlocomotion (Park et al., 2014; Basurto et al., 2015). However, to our knowledge, the effects of CBD on the PPI response of non-human primates (NHP) have yet to be assessed. It is known that manipulations of learning and memory-related areas, such as the hippocampus, can alter PPI responding (Kohl et al., 2013). Compared to rodents, NHPs have a distinct motor response to cannabinoid-related substances (Meschler et al., 2001) and display higher CB1 receptor densities in memory-related areas (Ong and Mackie, 1999). So, here we first analyzed the effects of CBD directly on the PPI response of capuchin monkeys and then evaluated the influence of a $\mathrm{CBD}$ pre-treatment on repeated MK-801-induced changes in the same PPI test.

\section{MATERIALS AND METHODS}

\section{Ethics Statement}

All the procedures herein complied with the Brazilian regulations for the scientific use of laboratory animals (Lei Arouca 11.794/2008), as well as the CONCEA/Brazil and NIH/USA guidelines for the care and use of laboratory animals, and were approved by the Animal Ethics Committee of the University of Brasilia (no. 131791/2013).

\section{Subjects and General Housing Conditions}

In total, seven capuchin monkeys (Sapajus spp.) were used, one male and six females, weighing between 2.5 and $5.0 \mathrm{~kg}$ at the beginning of the study. All subjects were housed and tested at the Primate Center of the University of Brasilia, Brazil. They were group or paired-housed under natural light, temperature and humidity conditions in standard cages $(3 \mathrm{~m} \times 3 \mathrm{~m} \times 1.8 \mathrm{~m})$ containing rope swings, nest boxes and natural substrate on the floor. Fresh food was provided daily at 07:00 h, consisting of a mixture of pieces of fruits and vegetables. Boiled eggs, nuts and cooked chicken breast were given several times a week, also at 07:00 h. Unconsumed items were removed at 17:00 h, while water and chow were available ad libitum.
Housing and maintenance conditions complied with the regulations of the Brazilian National Institute of Environment and Renewable Natural Resources (IBAMA). The animals were only deprived of food and water during the specific trials indicated in the procedure below. All subjects used had previous experience with the PPI protocol (Saletti et al., 2014).

\section{Startle Measurement and General Procedure}

Prepulse inhibition testing was performed in a transparent acrylic chamber $(60 \mathrm{~cm} \times 30 \mathrm{~cm} \times 30 \mathrm{~cm})$ placed above a wooden box $(45 \mathrm{~cm} \times 40 \mathrm{~cm} \times 40 \mathrm{~cm})$. Each subject was placed inside this chamber in such a way that its head protruded through an adjustable central neck hole located at the top. A transparent acrylic device $(30 \mathrm{~cm} \times 30 \mathrm{~cm} \times 25 \mathrm{~cm})$ was placed directly on top of the chamber, encompassing the subject's head. This device contained three speakers (model FT96H- frequency band $4 \mathrm{KHz} \sim 30 \mathrm{KHz}$; Fostex, Japan), each located $10 \mathrm{~cm}$ from the monkey's head and connected to a sound generator (O'Hara \& Co., Ltd., Japan). One speaker was positioned on each side of the animal's head and generated the startle stimuli. The third speaker was placed at the back of the device and emitted a constant $65 \mathrm{~dB}$ white noise. An accelerometer (model BDK3; Inntechno Japan Co.Ltd., Japan), connected to an amplifier (O'Hara \& Co., Ltd., Japan), was placed at the bottom of the chamber. When the subject was inside the chamber it stood on the accelerometer platform. The accelerometer captured the animal's whole-body movement and transmitted the data to be recorded on the Animal Startle software (PCI 6024E, developed by O'Hara \& Co., Ltd., Japan) that interfaced with the Windows XP system (for details see Saletti et al., 2014). A video camera (model \#1004124; Clone, Brazil) was connected to this experimental setup and monitored the animal during each session.

Testing was conducted 5 days a week, between 8:00 and 12:00 $\mathrm{h}$, in an acoustically isolated room located near the monkeys' home-cage. After a $10 \mathrm{~min}$ acclimatization period to the test room and setup described above, PPI testing was conducted. It consisted of 10 consecutive blocks of stimuli presentation, held at $60 \mathrm{~s}$ intervals. During each block, three different stimuli were randomly presented, also at $60 \mathrm{~s}$ intervals: a $115 \mathrm{~dB}$ pulse of $40 \mathrm{~ms}$ duration, an $80 \mathrm{~dB}$ prepulse of $20 \mathrm{~ms}$ duration and a prepulse-pulse combination with a $120 \mathrm{~ms}$ interval between the prepulse and pulse presentation. Stimuli intensity and duration were based on previous studies (Saletti et al., 2014, 2015). The startle response was recorded by the Animal Startle software system that measured the animals' body movements through changes in force detected by the accelerometer. The animals' body movements were recorded during a $600 \mathrm{~ms}$ post-stimuli interval and the peak amplitude registered following the pulse or prepulse+pulse stimulus of each trial was recorded as the startle amplitude.

\section{Experiment 1: Effects of CBD Treatment on PPI}

In the first experiment, $\mathrm{CBD}(0,15,30$, and $60 \mathrm{mg} / \mathrm{kg}$; volume of $1 \mathrm{~mL} / \mathrm{kg}$; STI Pharm, UK) was dissolved in a 1:19 solution of 
Tween 80 (Sigma-Aldrich, Brazil) and 0.9\% saline, respectively. Doses were based on previous studies in rodents (Moreira and Guimarães, 2005; Almeida et al., 2013; Levin et al., 2014). For the safety of the personnel involved and to insure correct intraperitoneal (ip) administrations, all animals were briefly exposed to the anesthetic isoflurane via inhalation, yet an effective anesthesia stage was never really attained.

All subjects were initially tested with vehicle and then treated with the three doses of CBD. Only one treatment was given on each test day, with a 2 -week interval between trials. The order in which the three CBD doses were given was randomly assigned for each animal. Each subject received the vehicle injection or a $\mathrm{CDB}$ dose and was then placed in the test chamber. After a $30 \mathrm{~min}$ interval, it was submitted to the PPI test procedure described above. Two females were excluded from the analyses due to data recording problems, totalizing five animals in experiment 1 (one male and four females).

\section{Experiment 2: Effects of CBD Pre-treatment Following Repeated MK-801 Treatment}

In this second experiment, the same seven monkeys were tested 4 months after the previous study. MK-801 (0.02 mg/kg; SigmaAldrich, Brazil) and CBD (60 mg/kg; STI Pharm, UK) were both dissolved in a 1:19 solution of Tween 80 (Sigma-Aldrich, Brazil) and $0.9 \%$ saline, respectively. The former was administered intramuscularly (im), whereas CBD was again given via ip route. The injection volume of both substances was $1 \mathrm{ml} / \mathrm{kg}$. The MK801 dose was based on our previous study (Saletti et al., 2015).

Each animal was given a MK-801 injection, once a week, during three consecutive weeks. Twenty minutes after each injection, the subject was tested in the same PPI procedure described above. On the 4th week of testing, each monkey was pre-treated with $\mathrm{CBD}$ and then 10 min later it received a $\mathrm{MK}$ 801 treatment. PPI testing was once again held $20 \mathrm{~min}$ after the MK-801 administration. Two weeks later, each animal was injected with vehicle and following a 20 min interval tested in the PPI protocol (VEH 2). To control for a habituation effect due to repeated testing, and considering that the same monkeys were used in both experiments, data from the vehicle trial of Experiment 1 were used as a second control session in this study (VEH 1).

\section{Behavioral and Statistical Analysis}

Data were expressed as the mean startle response or percentage of PPI + standard error of the mean (+S.E.M.). The data were normalized using the following calculation of the percentage of inhibition (Saletti et al., 2014, 2015):

$$
\frac{100 *(p-p p)}{p}
$$

where $p$ corresponds to the pulse-alone startle response and $p p$ to the prepulse+pulse response.

The data were normally distributed, according to the Shapiro-Wilk test. To establish a possible between-treatment effect (vehicle, MK-801 and CBD+MK-801) on the capuchins' startle amplitude and percentage of PPI, data from each experiment were analyzed using a one-way ANOVA for repeated measures (pulse and prepulse+pulse trials were analyzed separately). Whenever significant results were obtained, Fisher's LSD post hoc test was used for pair-wise comparison across treatments. Significance level for all tests was set at $p<0.05$. For Shapiro-Wilk and ANOVA analysis we used the IBM SPSS ${ }^{\circledR}$ version 20 software. For comparisons with $p<0.05$, we also calculated the effect sizes (effsize) using Matlab software ${ }^{\circledR}$ (version R2013a).

\section{RESULTS}

\section{Experiment 1: Effects of CBD Treatment on PPI}

In terms of the startle amplitude, a significant between-treatment effect was not observed for either the pulse $\left(F_{3,12}=0.566\right.$, $p=0.648$; Figure 1A) or prepulse+pulse trials $\left(F_{3,12}=1,375\right.$;
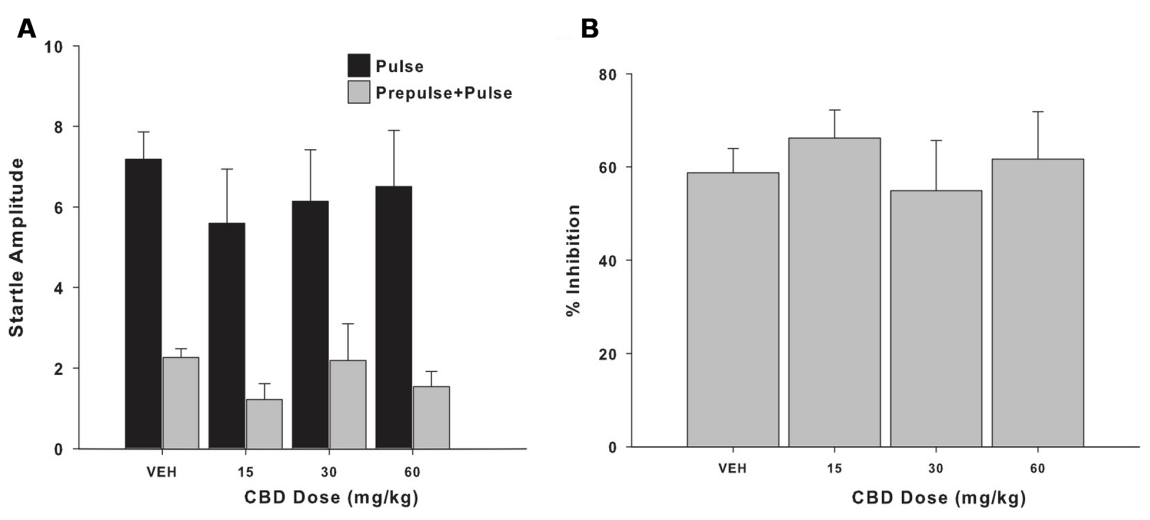

FIGURE 1 | (A) Mean (+SEM) startle amplitude of the capuchin monkeys $(n=5)$ in the pulse (black bars) and prepulse-pulse trials (gray bars) following the vehicle (VEH) and the three CBD treatments (15, 30, and $60 \mathrm{mg} / \mathrm{kg}$ ). (B) Mean (+SEM) percentage of prepulse inhibition (PPI) of the capuchin monkeys $(n=5)$ following the vehicle $(\mathrm{VEH})$ and the three $\mathrm{CBD}$ treatments $(15,30$, and $60 \mathrm{mg} / \mathrm{kg})$. 
$p=0.297$; Figure 1A), with the subjects' response remaining constant regardless of the treatment received. A similar profile was seen for the percentage of PPI when analyzing the data according to the treatment received $\left(F_{3,12}=0.368, p=0.778\right.$; Figure 1B) and over the course of the weeks of the experiment, regardless of the specific treatment received $\left(F_{3,12}=1.283\right.$, $p=0.325$; Figure 2).

\section{Experiment 2: Effects of CBD Pre-treatment on MK-801-Induced Changes in PPI}

Among the different pulse $\left(F_{5,30}=1.270, p=0.303\right.$; Figure 3) or prepulse + pulse trials $\left(F_{5,30}=1.800, p=0.143\right.$; Figure 3), significant differences were not observed. However, the percentage of PPI differed significantly between treatments $\left(F_{5,30}=4.052, p=0.006\right.$; Figure 4$)$. This parameter was significantly higher following all three MK-801 administrations, compared to the first vehicle administration [vs. MK-801(1): $p=0.009$, effsize $=1.498$; vs. MK-801(2): $p=0.026$, effsize $=0.983$; vs. MK-801(3): $p=0.005$, effsize $=1.743$ ]. The percentage of PPI after the CDB + MK-801 treatment was significantly lower than on the trials with only MK-801(1) and MK-801(3), being similar to the levels seen following both vehicle injections [vs. VEH 1: $p=0.183$; vs. MK-801(1): $p=0.02$, effsize $=0.718$; vs. MK-801(2): $p=0.512$; vs. MK-801(3): $p=0.013$, effsize $=0.878$; vs. VEH $2: p=0.954]$.

\section{DISCUSSION}

\section{CBD on Monkey PPI}

The results from Experiment 1 indicated that the CBD administration alone had no effect on the capuchin monkeys' startle amplitude or PPI response. Although to our knowledge this is the first study to evaluate such aspect in NHPs, similar

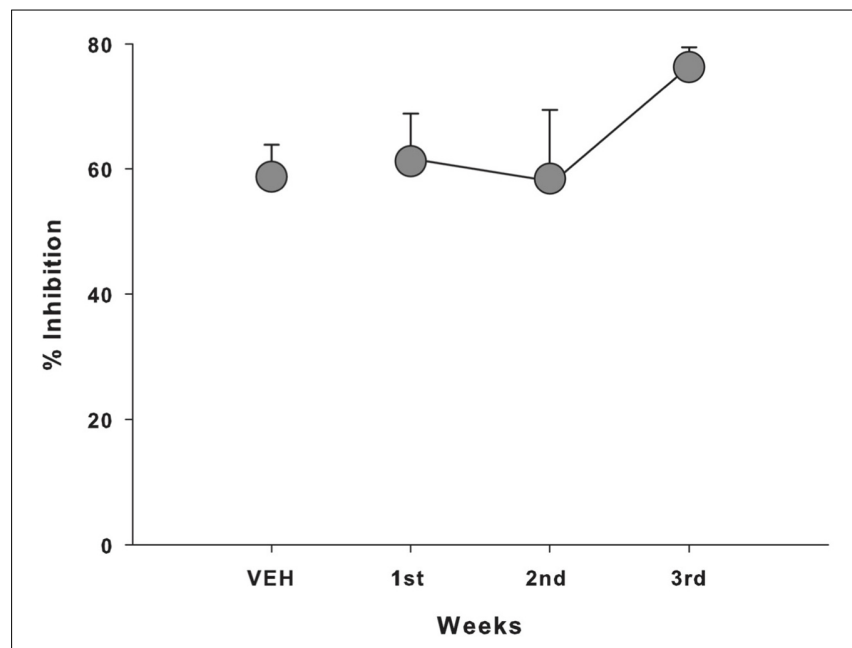

FIGURE 2 | Mean ( \pm SEM) percentage of PPI of the capuchin monkeys $(n=5)$ according to the week of Experiment 1, regardless of the CBD dose received; VEH, vehicle.
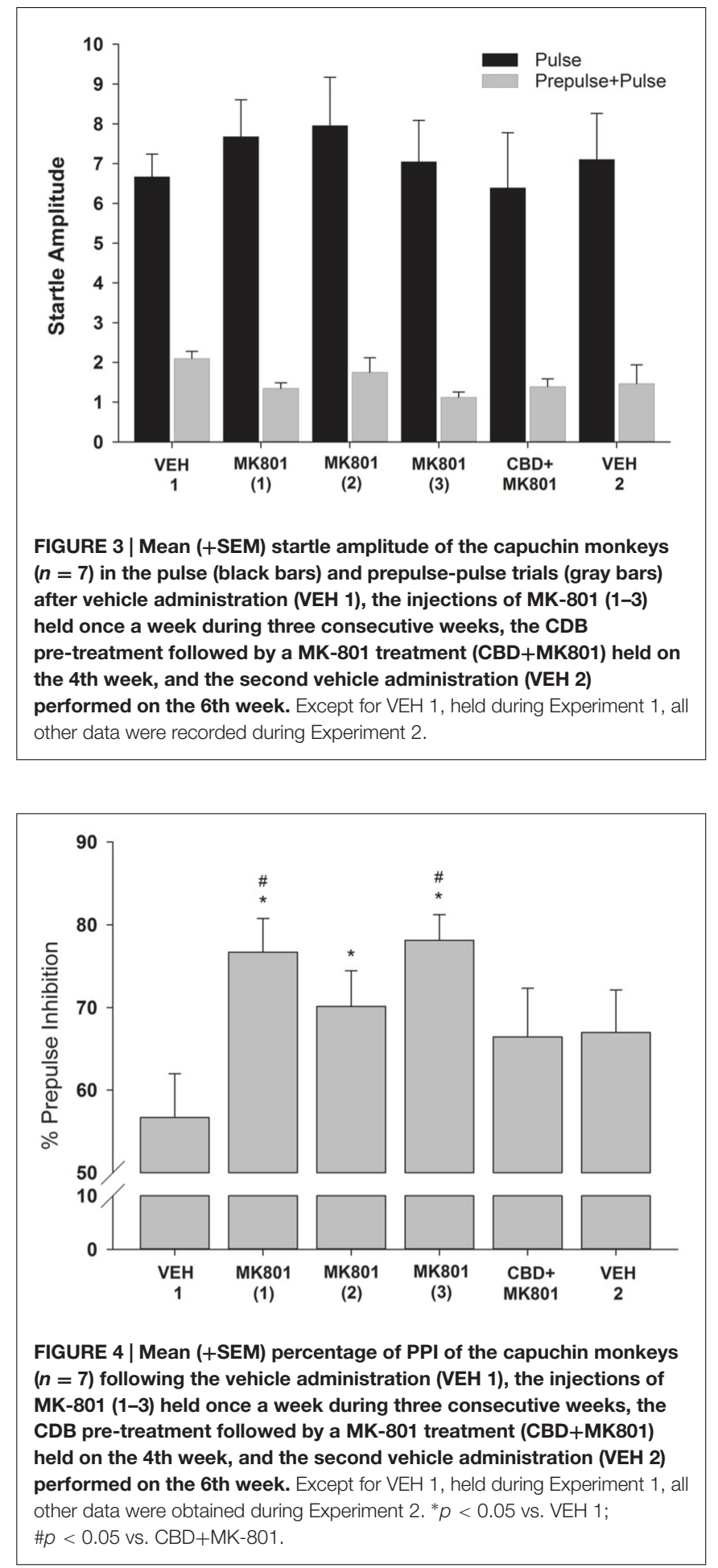

results have been observed in rodents (Long et al., 2006; Gomes et al., 2014; Levin et al., 2014; Pedrazzi et al., 2015). Long et al. (2006) and Gururajan et al. (2011) reported, however, that a systemic administration of CBD altered the startle response of rodents. In this case, the percentage of PPI decreased following a $10 \mathrm{mg} / \mathrm{kg}$ dose of CBD, whereas 3 and $30 \mathrm{mg} / \mathrm{kg}$ had no effect. 
This discrepancy may be partly due to species-specific differences, as the CB1 receptor density of rodents and primates differs in certain regions of the brain (Ong and Mackie, 1999), as well as their motor response to cannabinoid-related substances (Meschler et al., 2001). Important methodological aspects may also have contributed. Due to ethical restrictions and reduced sample size in monkey research, our subjects were submitted to the PPI procedure in a repeated-exposure design. Nonetheless, a temporal or drug-training effect does not seem to have influenced the present result as the percentage of PPI remained constant over the course of the procedure, regardless of the specific CBD treatment given. Thus, our results in capuchins suggest that CB1 receptor antagonism may have no effect on sensorimotor gating mechanisms.

\section{CBD Pre-treatment on MK-801 Induced PPI Enhancement}

MK-801 has been shown to induce schizophrenic-like behaviors in monkeys, such as deficits in memory-related processing (Ogura and Aigner, 1993; Buffalo et al., 1994; Harder et al., 1998; Harder and Ridley, 2000; Tsukada et al., 2005; Wang et al., 2012) and more recently in changes in PPI responding (Saletti et al., 2015). Although an acute $0.03 \mathrm{mg} / \mathrm{kg}$ dose of MK801 decreased the PPI of capuchin monkeys, repeated testing (with different doses) in the same setup diminished this effect possibly due to drug-induced ataxia or tolerance (Saletti et al., 2015).

In the present study, we opted to use a lower dose of MK801 to reduce such levels of ataxia. The $0.02 \mathrm{mg} / \mathrm{kg}$ dose was used in a repeated administration regimen, thereby leading to an increase in the monkeys' percentage of PPI. This result differs from the MK-801-induced decrease in PPI reported in rodents (Schulz et al., 2001; Gomes et al., 2014), considered to be an indicator of a psychotic-like effect of this drug. It also contrasts with the lack of effect observed for this dose in our previous study using the same animals (Saletti et al., 2015). In that instance, each subject received all possible treatments only once (vehicle, $0.01,0.02$, and $0.03 \mathrm{mg} / \mathrm{kg}$ ) in a pseudorandomized order, whereas only the $0.02 \mathrm{mg} / \mathrm{kg}$ dose was presently given on three consecutive trials. Thus the present increase in PPI, detected already on the first trial, seems unlikely to be due to a habituation effect considering the 5-month interval between the experiments, the similar PPI and startle amplitude levels seen during the vehicle control trials of the two studies ( $\approx 55 \%$ and 6 points, respectively), and the response stability seen on the last session of current study (VEH 2 vs. CBD+MK801). Ketamine, another NMDA antagonist, is also reported to increase the PPI response of healthy human volunteers when using a brief inter-stimulus interval (Braff et al., 2001; Duncan et al., 2001). The use of higher doses in rodents and distinct hippocampal NMDA receptor sensitivity could be important aspects contributing to the discrepancies between human and rodent PPI responding (Duncan et al., 2001). NMDA antagonists can block hippocampal long-term potentiation, with this effect being modified by pre-training or test familiarization through latent learning effect (Otnaess et al.,
1999; Ennaceur et al., 2011). The hippocampus is also known to be responsable for PPI response modulation (Kohl et al., 2013).

Interestingly, pre-treatment with CBD prevented the MK-801induced increase in the monkeys' PPI. Considering the large effect sizes values found ( $\approx 0.8$ or more; Sullivan and Feinn, 2012), we are able to conclude that the difference between the treatments is expressive. Nonetheless, the effects induced by both MK-801 and $\mathrm{CBD}$ seem related to their anxiogenic and anxiolytic profiles, respectively - an aspect that is highly relevant in the context of a startle response. In mice, MK-801 is reported to increase anxiety levels (Ennaceur et al., 2011), whereas CBD has been frequently linked to anxiolysis (Zuardi et al., 1982; Guimarães et al., 1990; Campos and Guimarães, 2008; Almeida et al., 2013). CBD seems to activate serotoninergic 5-HT1A receptors (Russo et al., 2005; Resstel et al., 2009; Soares et al., 2010; Gomes et al., 2011) and attenuate cardiovascular and/or behavioral responses associated with anxiety and panic in rats (Resstel et al., 2009; Soares et al., 2010).

Although CBD has been reported to reverse the PPI disruption induced by MK-801 (Long et al., 2006; Gomes et al., 2014) and amphetamine in rodents (Pedrazzi et al., 2015), our present results with capuchins fail to corroborate a possible antipsychotic effect for this compound in the context of sensorimotor gating. In the presence of only MK-801, the startle amplitude generally tended to decrease in the 'pulse' trials, yet increase in 'prepulse+pulse' trials. The latter, however, was also observed with subsequent treatments (CBD+MK-801 and VEH 2). The pre-treatment of the monkeys with $\mathrm{CBD}$ reversed this increase tendency in startle amplitude in PPI, with no visible changes in 'pulse' trials. Altogether, these results suggest that the CBD effects on PPI are unlikely to stem from a direct involvement in sensorimotor gating mechanisms. We suggest that the CBDinduced reversal of the MK-801 effects may be related to their anxiolytic and anxiogenic profiles, respectively (Zuardi et al., 1982; Ennaceur et al., 2011; Almeida et al., 2013), although this aspect was not directly investigated in the present study. Further studies are necessary to better elucidate the interplay between anxiety and schizophrenia, as well as the potential use of CBD as an antipsychotic drug, possibly using other NHP models as well.

\section{CONCLUSION}

In the present study, CBD alone had no effect on the PPI response of capuchin monkeys, yet blocked the increase in this response that was induced by NMDA receptor antagonism (MK-801). This effect may stem from a general anxiolytic rather than an antipsychotic effect, corroborating an anxiolytic profile of CBD in the PPI paradigm.

\section{AUTHOR CONTRIBUTIONS}

CT, PS, and RM: Conception and design, acquisition of data, or analysis and interpretation of data; drafting the article or 
revising it critically for important intellectual content. $\mathrm{MB}$ and $\mathrm{HN}$ : Drafting the article or revising it critically for important intellectual content.

\section{FUNDING}

This research was supported by FAP/DF grant to CT (no. 193.000.033/2012) and the SPS Asian Core Program. PS was

\section{REFERENCES}

Almeida, V., Levin, R., Peres, F. F., Niigaki, S. T., Calzavara, M. B., Zuardi, A. W., et al. (2013). Cannabidiol exhibits anxiolytic but not antipsychotic property evaluated in the social interaction test. Prog. Neuropsychopharmacol. Biol. Psychiatry 41, 30-35. doi: 10.1016/j.pnpbp.2012.10.024

Arai, S., Takuma, K., Mizoguchi, H., Ibi, D., Nagai, T., Takahashi, K., et al. (2008). Involvement of pallidotegmental neurons in methamphetamine- and MK-801induced impairment of prepulse inhibition of the acoustic startle reflex in mice: reversal by GABAB receptor agonist baclofen. Neuropsychopharmacology 33, 3164-3175. doi: 10.1038/npp.2008.41

Baker, D., Pryce, G., Giovannoni, G., and Thompson, A. J. (2003). The therapeutic potential of cannabis. Lancet Neurol. 2, 291-298. doi: 10.1016/ S1474- 4422(03)00381-8

Basurto, E., Flores, O. G., and Hoffman, K. L. (2015). Glycinamide prevents MK801-induced hyperactivity and deficits in object recognition memory in an animal model of positive and cognitive symptoms of schizophrenia. Schizophr. Res. 66, 349-350. doi: 10.1016/j.schres.2015.02.024

Braff, D. L., Geyer, M. A., and Swerdlow, N. R. (2001). Human studies of prepulse inhibition of startle: normal subjects, patient groups, and pharmacological studies. Psychopharmacology 156, 234-258. doi: 10.1007/s002130100810

Buffalo, E. A., Gillam, M. P., Allen, R. R., and Paule, M. G. (1994). Acute behavioral effects of MK-801 in rhesus monkeys: assessment using an operant test battery. Pharmacol. Biochem. Behav. 48, 935-940. doi: 10.1016/0091-3057(94)90 203-8

Campos, A. C., and Guimarães, F. S. (2008). Involvement of 5HT1A receptors in the anxiolytic-like effects of cannabidiol injected into the dorsolateral periaqueductal gray of rats. Psychopharmacology 199, 223-230. doi: 10.1007/ s00213-008-1168-x

Cristino, L., de Petrocellis, L., Pryce, G., Baker, D., Guglielmotti, V., and Di Marzo, V. (2006). Immunohistochemical localization of cannabinoid type 1 and vanilloid transient receptor potential vanilloid type 1 receptors in the mouse brain. Neuroscience 139, 1405-1415. doi: 10.1016/j.neuroscience.2006.02.074

Di Marzo, V., Bisogno, T., and De Petrocellis, L. (2001). Anandamide: some like it hot. Trends Pharmacol. Sci. 22, 346-349. doi: 10.1016/S0165-6147(00)01712-0

Duncan, E. J., Madonick, S. H., Parwani, A., Angrist, B., Rajan, R., Chawravorty, S., et al. (2001). Clinical and sensorimotor gating effects of ketamine in normals. Neurophychofarmacology 25, 72-83. doi: 10.1016/S0893-133X(00)00240-2

Ennaceur, A., Michalikova, S., Van Rensburg, R., and Chazot, P. L. (2011). MK801 increases the baseline level of anxiety in mice introduced to a spatial memory task without prior habituation. Neuropharmacology 61, 981-991. doi: 10.1016/j.neuropharm.2011.06.027

Gomes, F. V., Issy, A. C., Ferreira, F. R., Viveros, M.-P., Del Bel, E. A., and Guimaraes, F. S. (2014). Cannabidiol attenuates sensorimotor gating disruption and molecular changes induced by chronic antagonism of NMDA receptors in mice. Int. J. Neuropsychopharmacol. 18, yu041-yu041. doi: 10.1093/ijnp/pyu041

Gomes, F. V., Resstel, L. B. M., and Guimarapes, F. S. (2011). The anxiolyticlike effects of cannabidiol injected into the bed nucleus of the stria terminalis are mediated by 5-HT1A receptors. Psychopharmacology 213, 465-473. doi: 10.1007/s00213-010-2036-z

Guimarães, F. S., Chiaretti, T. M., Graeff, F. G., and Zuardi, A. W. (1990). Antianxiety effect of cannabidiol in the elevated plus-maze. Psychopharmacology 100, 558-559. doi: 10.1007/BF02244012

Gururajan, A., Taylor, D. A., and Malone, D. T. (2011). Effect of cannabidiol in a MK-801-rodent model of aspects of schizophrenia. Behav. Brain Res. 222, 299-308. doi: 10.1016/j.bbr.2011.03.053 recipient of a doctoral fellowship from $\mathrm{CNPq}, \mathrm{MB}$ a research fellowship from CNPq (304041/2015-7) and RM a post-doctoral fellowship from CNPq (233647/2014-7).

\section{ACKNOWLEDGMENT}

We thank G. V. da Silva, A. Araujo, R. S. Oliveira, and C. D. Azevedo for the excellent animal care.

Hampson, A. J., Grimaldi, M., Axelrod, J., and Wink, D. (1998). Cannabidiol and $\Delta$ 9-tetrahydrocannabinol are neuroprotective antioxidants. Proc. Natl. Acad. Sci. U.S.A. 95, 8268-8273.

Harder, J. A., Aboobaker, A. A., Hodgetts, T. C., and Ridley, R. M. (1998). Learning impairments induced by glutamate blockade using dizocilpine (MK-801) in monkeys. Br. J. Pharmacol. 125, 1013-1018. doi: 10.1038/sj.bjp.0702178

Harder, J. A., and Ridley, R. M. (2000). The 5HT1A antagonist, WAY 100635, alleviates cognitive impairments induced by dizocilpine ( MK-801 ) in monkeys. Neuropharmacology 39, 547-552. doi: 10.1016/S0028-3908(99)00179-3

Hikichi, H., Kaku, A., Karasawa, J., and Chaki, S. (2013). Stimulation of metabotropic glutamate $(\mathrm{mGlu}) 2$ receptor and blockade of mglu1 receptor improve social memory impairment elicited by MK-801 in rats. J. Pharmacol. Sci. 122, 10-16. doi: 10.1254/jphs.13036FP

Hoffman, D. C., Donovan, H., and Cassella, J. V. (1993). The effects of haloperidol and clozapine on the disruption of sensorimotor gating induced by the noncompetitive glutamate antagonist MK-801. Psychopharmacology 111, 339-344. doi: 10.1007/BF02244950

Karamihalev, S., Prickaerts, J., and van Goethem, N. P. (2014). Donepezil and the alpha-7 agonist PHA 568487, but not risperidone, ameliorate spatial memory deficits in a subchronic MK-801 mouse model of cognitive impairment in schizophrenia. Behav. Brain Res. 272, 248-251. doi: 10.1016/j.bbr.2014.07.017

Kohl, S., Heekeren, K., Klosterkotter, J., and Kuhn, J. (2013). Prepulse inhibition in psychiatric disorders-apart from schizophrenia. J. Psychiatr. Res. 47, 445-452. doi: 10.1016/j.jpsychires.2012.11.018

Levin, R., Peres, F. F., Almeida, V., Calzavara, M. B., Zuardi, A. W., Hallak, J. E. C., et al. (2014). Effects of cannabinoid drugs on the deficit of prepulse inhibition of startle in an animal model of schizophrenia: the SHR strain. Front. Pharmacol. 5:10. doi: 10.3389/fphar.2014.00010

Leweke, F. M., Piomelli, D., Pahlisch, F., Muhl, D., Gerth, C. W., Hoyer, C., et al. (2012). Cannabidiol enhances anandamide signaling and alleviates psychotic symptoms of schizophrenia. Transl. Psychiatry 2:e94. doi: 10.1038/tp.2012.15

Long, L. E., Malone, D. T., and Taylor, D. A. (2006). Cannabidiol reverses MK-801induced disruption of prepulse inhibition in mice. Neuropsychopharmacology 31, 795-803. doi: 10.1038/sj.npp. 1300838

Mechoulam, R., Parker, L. A., and Gallily, R. (2002). Cannabidiol: an overview of some pharmacological aspects. J. Clin. Pharmacol. 42, 11S-19S. doi: 10.1177/ 0091270002238789

Meschler, J., Howlett, A., and Madras, B. (2001). Cannabinoid receptor agonist and antagonist effects on motor function in normal and 1-methyl4-phenyl-1,2,5,6- tetrahydropyridine (MPTP)-treated non-human primates. Psychopharmacology 156, 79-85. doi: 10.1007/s002130100728

Moreira, F. A., and Guimarães, F. S. (2005). Cannabidiol inhibits the hyperlocomotion induced by psychotomimetic drugs in mice. Eur. J. Pharmacol. 512, 199-205. doi: 10.1016/j.ejphar.2005.02.040

Ogura, H., and Aigner, T. G. (1993). MK-801 impairs recognition memory in rhesus monkeys: comparison with cholinergic drugs. J. Pharmacol. Exp. Ther. 266, 60-64.

Ong, W., and Mackie, K. (1999). A light and electron microscopic study of the CB1 cannabinoid receptor in primate brain. Neuroscience 92, 1177-1191. doi: 10.1016/S0306-4522(99)00025-1

Otnaess, M. K., Brun, V. H., Moser, M. B., and Moser, E. I. (1999). Pretraining prevents spatial learning impairment after saturation of hippocampal long-term potentiation. J. Neurosci. 19, 1-5.

Park, S. J., Lee, Y., Oh, H. K., Lee, H. E., Lee, Y., Ko, S. Y., et al. (2014). Oleanolic acid attenuates MK-801-induced schizophrenia-like behaviors in mice. Neuropharmacology 86, 49-56. doi: 10.1016/j.neuropharm.2014.06.025 
Pedrazzi, J. F. C., Issy, A. C., Gomes, F. V., Guimarães, F. S., and Del-Bel, E. A. (2015). Cannabidiol effects in the prepulse inhibition disruption induced by amphetamine. Psychopharmacology 232, 3057-3065. doi: 10.1007/s00213-0153945-7

Resstel, L. B. M., Tavares, R. F., Lisboa, S. F. S., Joca, S. R. L., Corrêa, F. M. A., and Guimarapes, F. S. (2009). 5-HT1A receptors are involved in the cannabidiolinduced attenuation of behavioural and cardiovascular responses to acute restraint stress in rats. Br. J. Pharmacol. 156, 181-188. doi: 10.1111/j.1476-5381. 2008.00046.x

Russo, E. B., Burnett, A., Hall, B., and Parker, K. K. (2005). Agonistic properties of cannabidiol at 5-HT1A receptors. Neurochem. Res. 30, 1037-1043. doi: 10.1007/ s11064-005-6978-1

Saletti, P. G., Maior, R. S., Hori, E., Almeida, R. M., De Nishijo, H., and Tomaz, C. (2014). Whole-body prepulse inhibition protocol to test sensorymotor gating mechanisms in monkeys. PLOS ONE 9:e105551. doi: 10.1371/journal.pone. 0105551

Saletti, P. G., Maior, R. S., Hori, E., Nishijo, H., and Tomaz, C. (2015). Sensorimotor gating impairments induced by MK-. (801.A20)treatment may be reduced by tolerance effect and by familiarization in monkeys. Front. Pharmacol. 6:204. doi: 10.3389/fphar.2015.00204

Schulz, B., Fendt, M., Pedersen, V., and Koch, M. (2001). Sensitization of prepulse inhibition deficits by repeated administration of dizocilpine. Psychopharmacology 156, 177-181. doi: 10.1007/s002130100776

Soares, V. P., Campos, A. C., Bortoli, V. C., de Zangrossi, H., Guimarães, F. S., and Zuardi, A. W. (2010). Intra-dorsal periaqueductal gray administration of cannabidiol blocks panic-like response by activating 5-HT1A receptors. Behav. Brain Res. 213, 225-229. doi: 10.1016/j.bbr.2010.05.004

Sullivan, G. M., and Feinn, R. (2012). Using effect size - or why the p value is not enough. J. Grad. Med. Educ. 4, 279-282. doi: 10.4300/JGME-D-1200156.1

Thomas, A., Baillie, G. L., Phillips, A. M., Razdan, R. K., Ross, R. A., and Pertwee, R. G. (2007). Cannabidiol displays unexpectedly high potency as an antagonist of CB1 and CB2 receptor agonists in vitro. Br. J. Pharmacol. 150, 613-623. doi: 10.1038/sj.bjp.0707133

Tsukada, H., Nishiyama, S., Fukumoto, D., Sato, K., Kakiuchi, T., and Domino, E. F. (2005). Chronic NMDA antagonism impairs working memory, decreases extracellular dopamine, and increases D1 receptor binding in prefrontal cortex of conscious monkeys. Neuropsychopharmacology 30, 1861-1869. doi: 10.1038/ sj.npp.1300732

Vilela, L. R., Gomides, L. F., David, B. A., Antunes, M. M., Diniz, A. B., Moreira, F., et al. (2015). Cannabidiol rescues acute hepatic toxicity and seizure induced by cocaine. Mediat. Inflamm. 2015, 1-12. doi: 10.1155/2015/523418

Wang, J., Chen, Y., Carlson, S., Li, L., Hu, X., and Ma, Y. (2012). Interactive effects of morphine and scopolamine, MK-801, propanolol on spatial working memory in rhesus monkeys. Neurosci. Lett. 523, 119-124. doi: 10.1016/j.neulet. 2012.06.056

Xing, J., and Li, J. (2007). TRPV1 receptor mediates glutamatergic synaptic input to dorsolateral periaqueductal gray (dl-PAG) neurons. J. Neurophysiol. 97, 503-511. doi: 10.1152/jn.01023.2006

Yoshimi, N., Futamura, T., and Hashimoto, K. (2015). Improvement of dizocilpine- induced social recognition deficits in mice by brexpiprazole, a novel serotonin- dopamine activity modulator. Eur. Neuropsychopharmacol. 25, 356-364. doi: 10.1016/j.euroneuro.2014.12.014

Zuardi, A. W., Crippa, J. A., Hallak, J. E. C., Bhattacharyya, S., Atakan, Z., Martin-Santos, R., et al. (2012). A critical review of the antipsychotic effects of cannabidiol: 30 years of a translational investigation. Curr. Pharm. Des. 18, 5131-5140. doi: 10.2174/138161212802884681

Zuardi, A. W., Rodrigues, J. A., and Cunha, J. M. (1991). Effects of cannabidiol in animal models predictive of antipsychotic activity. Psychopharmacology 104, 260-264. doi: 10.1007/BF02244189

Zuardi, A. W., Shirakawa, I., Finkelfarb, E., and Karniol, I. G. (1982). Action of cannabidiol on the anxiety and other effects produced by $\triangle 9$-THC in normal subjects. Psychopharmacology 76, 245-250. doi: 10.1007/BF00432554

Conflict of Interest Statement: The authors declare that the research was conducted in the absence of any commercial or financial relationships that could be construed as a potential conflict of interest.

Copyright (c) 2017 Saletti, Maior, Barros, Nishijo and Tomaz. This is an open-access article distributed under the terms of the Creative Commons Attribution License (CC BY). The use, distribution or reproduction in other forums is permitted, provided the original author(s) or licensor are credited and that the original publication in this journal is cited, in accordance with accepted academic practice. No use, distribution or reproduction is permitted which does not comply with these terms. 